\title{
Biodeterminism and pseudo-objectivity as obstacles for the emerging field of archaeogenetics
}

\author{
Martin Furholt \\ Department of Archaeology, Conservation and History, University of Oslo, Oslo, Norway \\ Email: Martin.furholt@iakh.uio.no
}

Michael Blakey presents a principled attack on the resurgence of pseudoscientific racism, which, as he argues, is seeping into the work of the most highly rated, best-regarded authorities of the international scientific community. Blakey attacks, powerfully, the old and clearly debunked idea of races as a biological thing, and points to the structural socio-economic background for its repeated zombie-like return. The paper will probably spark controversy, because it situates this observation in a broad sociopolitical context of overt and hidden racism and the ideological justification of old and current social inequality and injustice. It fiercely criticizes attempts by leading geneticists, most notably David Reich, to reconsider race science as an attempt to roll back the post-war scientific consensus that human races are socially constructed entities, by falsely claiming to pursue an unideological, objective look at what would be 'biological facts'. Blakey identifies this as part of the larger contradictory, yet interconnected, trends of, on the one hand, claiming to ignore the existence of the social category of race and denying the effects of racism, while, on the other hand, trying to naturalize social inequalities by referring to different, supposedly genetically determined qualities of 'individuals', or 'groups', which are thinly veiled euphemisms for race. Blakey contextualizes this historically, showing how the invention of modern racism is tightly connected to the emergence of colonialism and capitalism, serving as ideological justification for both systems of exploitation. In a similar manner, the current attempt to explain social differences in educational or economic success and in sociocultural patterns as being grounded in supposed biological differences is a political endeavour, whether or not it is intended by its protagonists, which plays into the hands of those political forces that want to justify and further intensify current levels of inequality (both nationally and globally). This is not a new argument, and Blakey himself has published on these issues before, but in the light of the new importance of genetics in many fields of research, including archaeology, what he has to say is clearly important. I do not want to engage here in detail with all of Blakey's arguments. Instead, given the theme of this journal and my role as a prehistoric archaeologist, I would like to consider Blakey's paper in the wider context of interdisciplinarity between geneticists and archaeologists, a context for which Blakey's more directed attack on the resurgence of pseudoscientific racism is highly relevant. This relevance is, I believe, first of all to be found in Blakey's fundamental critique of biodeterminism as an ideological mindset with severe political connotations, and second in the notion of scientific objectivity in general. Both issues speak to central points of conflict, or misunderstandings, between geneticists and archaeologists in the newly emerging field of archaeogenetics.

We archaeologists have found ourselves facing a veritable rollback of seemingly long-overcome notions of static cultures and a biologization of social identities, something that is clearly connected to the idea of races (Müller 2013; Heyd 2017; Furholt 2018; Frieman and Hofmann 2019). And this rollback is connected to the massive impact of ancient-DNA studies on archaeology. The premise that prehistoric communities were closed, internally homogeneous social entities with a shared uniform culture and a shared genetic ancestry, collectively migrating across the Eurasian continent, was invented by fascist ideologues such as Gustaf Kossinna in order to further right-wing, nationalist and racist political goals and to justify territorial claims in

\footnotetext{
(c) The Author(s), 2020. Published by Cambridge University Press. This is an Open Access article, distributed under the terms of the Creative Commons Attribution-NonCommercial-NoDerivatives licence (http://creativecommons.org/licenses/by-nc-nd/4.0/), which permits non-commercial re-use, distribution, and reproduction in any medium, provided the original work is unaltered and is properly cited. The written permission of Cambridge University Press must be obtained for commercial re-use or in order to create a derivative work.
} 
neighbouring countries more than 100 years ago. Such a narrative has been repeatedly deconstructed by anthropologists and archaeologists during the last 100 years (Barth 1982; Boas 1940; Childe 1933; Hodder 1982; Lüning 1972; Müller 2001; Wotzka 1993). Yet, and shockingly, this is exactly the kind of narrative that is repopularized in the context of the new archaeogenetic studies which have had such a profound impact on archaeology (Allentoft et al. 2015; Haak et al. 2015; Olalde et al. 2019). There is, of course, no question that there are nuanced, more detailed and well-argued narratives (for example Kristiansen et al. 2017) put out to make sense of the ancientDNA data, while a certain degree of simplification is by definition what a model does. But it is disconcerting that many of the narratives put forward, especially in the popular media (Barras 2019), convey the impression that we as archaeologists would support a view of prehistory that is made up of closed ethnic groups of people, defined by a uniform and differential culture and biology, who fight each other, extinguish each other and take each other's women (betraying the gender assumptions that reign in the background - discussed in Furholt 2019b; Frieman and Hofmann 2019). It should be disconcerting that such a scenario is similar to the world view of the new right groups, including white supremacists and neofascists, which are more and more emerging as a real threat to our relatively liberal societies (Furholt 2019a). This is not merely theoretical. The new archaeogenetic data are actively used in far-right Internet forums to promote their nefarious agendas (as well discussed in Frieman and Hofmann 2019). What we do is obviously not politically neutral.

Nevertheless, although Blakey opens his article denouncing the fetishization of DNA in Western science and society, I would like to promote a more positive starting point, acknowledging that genetic research has had a positive impact on prehistoric archaeology in the last few years and arguing that the emerging field of archaeogenetics potentially represents a significant and highly welcome additional source of information for our understanding of prehistory. The somewhat problematic start of the archaeogenetic endeavour is not to be attributed to individual people, nor would I lay blame on a whole discipline. In fact, I would allocate the responsibility for the use of flawed archaeological units to conceptualize and model the simultaneous dynamics of social interaction and biological admixture processes to my own archaeological community. We have failed to sufficiently introduce the theoretical state of the art concerning social-group composition and social interaction into the new archaeogenetic field. So while we have to conclude that there are conceptual problems and misunderstandings between archaeologists and geneticists, we are not talking about a divide between the two fields involved, but rather about a set of conceptual disagreements that are contentious within both disciplines. These debates have to be taken on if we want this emerging field to have positive effects on our understandings of prehistory. And this is where Blakey's arguments are especially useful. The way most archaeogenetic papers systematically downplay social conditions and human agency as factors in human (pre-)history (Bandelt, Macaulay and Richards 2003; Hofmann 2015) is clearly based, to different degrees, on the biodeterministic illusion Blakey calls out. It is also mostly paired with a positivist belief in objective scientific data, a notion that allows the scientists to claim innocence from all political consequences of their work.

Blakey also puts a finger on the conceptual divide between the supposedly non-ideological facts of nature revealed through objective scientific reasoning (as opposed to the ideology-laden social sciences) - the idea that biological data and categories could be in any way stripped of their underlying political and sociocultural value judgements. It is the idea of a nature-culture divide all over again. If we do not acknowledge that scientific data and categories of inquiry are socially constructed, interdisciplinarity will go nowhere. It seems that decades of theoretical discussions on this in philosophical and archaeological circles have not had much effect on day-to-day archaeological and archaeogenetic practices. Blakey's very pointed and dense text reminds us with great power of the obvious, yet crucial, fact that categorization, including the creation of scientific categories, is determined by and serves socio-economic and political interests. We cannot claim that what we are doing, as archaeologists or archaeogeneticists, is a neutral, objective laying out of 
facts, and we should not hesitate to challenge our colleagues who claim to do so. To translate Blakey's critique of Reich into a European context - which I would like to do because that is the field with which I am more familiar - it should be obvious that in the same way as race is an ideological construct, so too are other categorizations of humans used in European archaeology and in archaeogenetic studies. Here the most critical examples are the essentialization of social identities, like gender stereotypes and ethnicities modelled after modern nation states. The same could be argued for the recurring claims of violence, war and social inequality as inevitable characteristics of human societies, projecting them back into deep prehistory, on shaky empirical foundations. When the narratives connected to the newly found ancient-DNA data reproduce modern Western tropes about ethnic identities, gender relations and the role of war and violence in intergroup relations, we cannot really fall back on the defence that it is something that objectively follows from our neutral reading of the data. All the relevant categories, the populations, cultures, migrations and population replacements, really just reproduce the categories inserted by us and projected back into prehistory. This not only is intellectually lazy, but also prevents us from really gaining new knowledge about the past. This is even more unfortunate, as it is well-established wisdom that the concept of static cultures blatantly misrepresents both the archaeological record (Hofmann 2015; Vander Linden 2016; Furholt 2018; 2019b) and the anthropological knowledge of non-state social organization (e.g. Cameron 2013). Do we really have to, begrudgingly, succumb to acknowledging a prehistory that 'we may not like' - because it is filled with violent misogynist hordes from the East, forming biologically defined groups of young males, who bully their way through Europe, killing and raping themselves into our gene pool (perhaps a little unfairly challenging the well-argued piece by Kristiansen et al. 2017, but clearly expressed in its popular adaptation by Barras 2019)? Is it not our responsibility to counter such narratives, which reproduce the right-wing's view of human history as a perpetual clash of cultures? Especially when we actually know that it was us who inserted these ideas into our models in the first place? So it is clearly necessary to rethink our categories if we want to avoid giving ideological ammunition to nefarious political forces, but more fundamentally it is a prerequisite for arriving at any new ideas about the past.

Is it not actually an exciting challenge for the new archaeogenetic project to create models that consider other forms of group organization than the ones known for our own modern world? Would it not be an innovative take to explore the temporal and spatial dynamics of population histories in periods before state borders circumscribed and regulated peoples' movements and biological admixtures? Blakey's critique of biodeterminism and the notion of scientific objectivity is not only an invitation to self-reflection, but we should take it as an opportunity to think of ways forward in creating a truly interdisciplinary archaeogenetic research agenda.

Archaeological Dialogues (2020), 27, 25-27

doi: $10.1017 / \mathrm{S} 1380203820000069$

\title{
The strange afterlife of biodeterministic imagination
}

\author{
Whitney Battle-Baptiste
}

Department of Anthropology, University of Massachusetts Amherst, Amherst, Massachusetts, USA

Email: wbbaptiste@anthro.umass.edu

After the Egyptian and Indian, the Greek and Roman, the Teuton and Mongolian, the Negro is a sort of seventh son, born with a veil, and gifted with second-sight in this American world - a world which yields him no true self-consciousness, but only lets him see himself through the revelation of the other world. It is a peculiar sensation, this double-consciousness, 